\title{
The Nine-point Circle.
}

By R. F. Davis, M.A.

The nine-point circle of a triangle touches the inscribed circle.

\section{FIGURE 2.}

I. Let $A B C$ be a triangle, having $-C$ greater than $\angle B$, $\mathrm{D}, \mathrm{E}, \mathrm{F}$ the middle points of the sides, and $\mathrm{AX}$ perpendicular to $\mathrm{BC}$.

Then the upper segment of the nine-point circle cut off by DX contains an angle $\mathrm{C}-\mathrm{B}$; and conversely.

\section{Figure 3.}

II. If $\mathrm{AP}$ bisect the angle $\mathrm{A}$ and meet the base $\mathrm{BC}$ in $\mathrm{P}$, and $A C^{\prime}$ be taken along $A B$ equal to $A C$; then $P^{\prime} C^{\prime}$ touches the inscribed circle. Also $\angle \mathrm{BPC}^{\prime}=\angle \mathrm{C}-\angle \mathrm{B}$.

For the triangles $\mathrm{APC}, \mathrm{APC}$ are congruent; hence the perpendiculars IM, $\mathrm{IM}^{\prime}$ on $\mathrm{PC}, \mathrm{PC}^{\prime}$ respectively are equal.

Figure 4.

III.

$$
\mathrm{DM}^{2}=\mathrm{DP} \cdot \mathrm{DX}
$$

For

$$
\begin{aligned}
\mathrm{HI}^{2} & =\mathrm{HC}^{2} \\
& =\mathrm{HD} \cdot \mathrm{HK} \\
& =\mathrm{HP} \cdot \mathrm{HA} ;
\end{aligned}
$$

and the projections of $\mathrm{HI}, \mathrm{HP}, \mathrm{HA}$ on $\mathrm{BC}$ are DM, DP, DX.

\section{Figure 5.}

IV. Let $O$ be a fixed point on the tangent at $A$ to a fixed circle $S$, and points $P, Q$ be taken (the one on $O A$ and the other on $O A$ produced) such that $O A^{2}=O P . O Q$, then the segment of a circle $\Sigma$, described through $O, Q$ and containing an angle equal to the external angle between the tangents to $S$ from $\mathrm{P}$, touches the circle $\mathrm{S}$. 
For if $\mathrm{PR}$, the second tangent to $\mathrm{S}$ from $\mathrm{P}$, be drawn, and $\mathrm{OR}$ produced to meet $\mathrm{S}$ in $\mathrm{T}$, since

$$
\mathrm{OR} . \mathrm{OT}=\mathrm{OA}^{2}=\mathrm{OP} . \mathrm{OQ} \text {, }
$$

therefore

$$
\angle \mathrm{OTQ}=\angle \mathrm{OPR}
$$

therefore the point $\mathrm{T}$ lies on $\mathrm{\Sigma}$.

Again, drawing the tangent $\mathrm{TU}$ to $\mathrm{S}$ at $\mathrm{T}$ to meet $\mathrm{PR}$ produced in $\mathrm{U}$;

$$
\angle \mathrm{UTR}=\angle \mathrm{URT}=\angle \mathrm{ORP}=\angle \mathrm{OQT}
$$

therefore TU touches $\mathrm{Y}$ at $\mathrm{T}$.

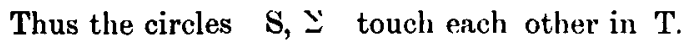

V. The application of Iv. is fairly obvious. Since in Figure 4 ,

$$
\mathrm{DM}^{2}=\mathrm{DP} . \mathrm{DX}(\mathrm{III}) \text {, }
$$

the segmental circle upon DX, containing an angle

$$
\mathrm{BPC}^{\prime}=\mathrm{C}-\mathrm{B}(\mathbf{I r} .) \text {, }
$$

touches the inscribed circle ( $\mathrm{v}$.$) . But ( \mathrm{I}$.$) the former circle is none$ other than the nine-point circle. 